\title{
Examination of Ultrastructural Mechanisms of Vitamin E Efficacy to Prevention of Ischemia-Reperfusion Injury in the Lung After Cardiopulmonary Bypass
}

\author{
M Acipayam*, G Huseyinova**, H Sunar*, S Canbaz*, E Duran*. \\ * Department of Cardiovascular Surgery, School of Medicine, Trakya University, Edirne, \\ Turkey \\ ** Department of Pathology, School of Medicine, Trakya University, Edirne, Turkey
}

OBJECTIVES: In this study, it was aimed that to examine the efficiacy of vitamin $\mathrm{E}$ as macromolecular structure to prevent ischemia-reperfusion injury in the lung after cardiopulmonary bypass.

METHODS: Totaly, 35 patients who divided into two groups were taken to the study.

Group I: There were17 patients. $50 \mathrm{cc} \mathrm{NaCl} \mathrm{\% 0.9} \mathrm{which} \mathrm{includes} 300 \mathrm{mg}$ vitamin $\mathrm{E}$ (alphatocopherol) administrated through venous cannula at 5 minutes before initiation the total cardiopulmonary bypass.

Group II: There were 18 patients. Same amount $\mathrm{NaCl} \% 0.9$ that not contains vitamin $\mathrm{E}$ given those patients at the same period.

For these two groups, lung tissue specimens were taken three times before applying the cross-clamp to the aorta, 30 and 60 minutes after the removal of the aortic cross-clamp. Later, specimens were histopathologically examined with the help of Sem-100B and Jeol-10-10 electron microscopy.

RESULTS: Significant pathological changes were seen in haemato-alveolar wall in group II. Stasis, interseptal and interstitial oedema, diapedesis, distrophia and beginning of fibrosis (activation of fibroblast) were detected (figure 1).

Haemato-alveolar wall damage was prominantly reduced in group I. It was detected that organels of alveolar and endothelial cells cytoplasm were not disturbed and basal membranes were strict (figure 2). Increase of phagolysosom concentration in cytoplasma of macrophage was prominent.

CONCLUSIONS: In our opinion; vitamine E stabilizes the lipoprotein membranes of haematoalveolar barrier and prevents the existence of free radicals and heals the metabolism processes [14]. In addition, it prevents oedema formation and transcellular diapedesis between the alveolocyte endothel and basal membrane. It also increases phagocytic activity of macrophages.

\section{REFERENCES}

1-Makar T.K et al.,Vitamin E, ascorbate, glutathione, glutathione disulfide and enzymes of glutathione metabolism in cultures of chick astrocytes and neurons, J Neurochem (1994) 62:45-43. 2-Rothman S.M et al., Glutamate and the pathophysiology of hypoxic-ischemic brain damage, Ann Neurol; (1986)19:105-111.

3-Murray R.K et al., Harper's Biochemistry, twenty-first edition, Los Altos; Appleton\&Lange (1988):139.

4- Canbaz $\mathrm{S}$ et al., The effects of intracoronary administration of vitamin $\mathrm{E}$ on myocardial ischemia-reperfusion injury during coronary artery surgery. The Thoracic and Cardiovascular Surgeon; (2003)51:57-61. 


\section{FIGURES}
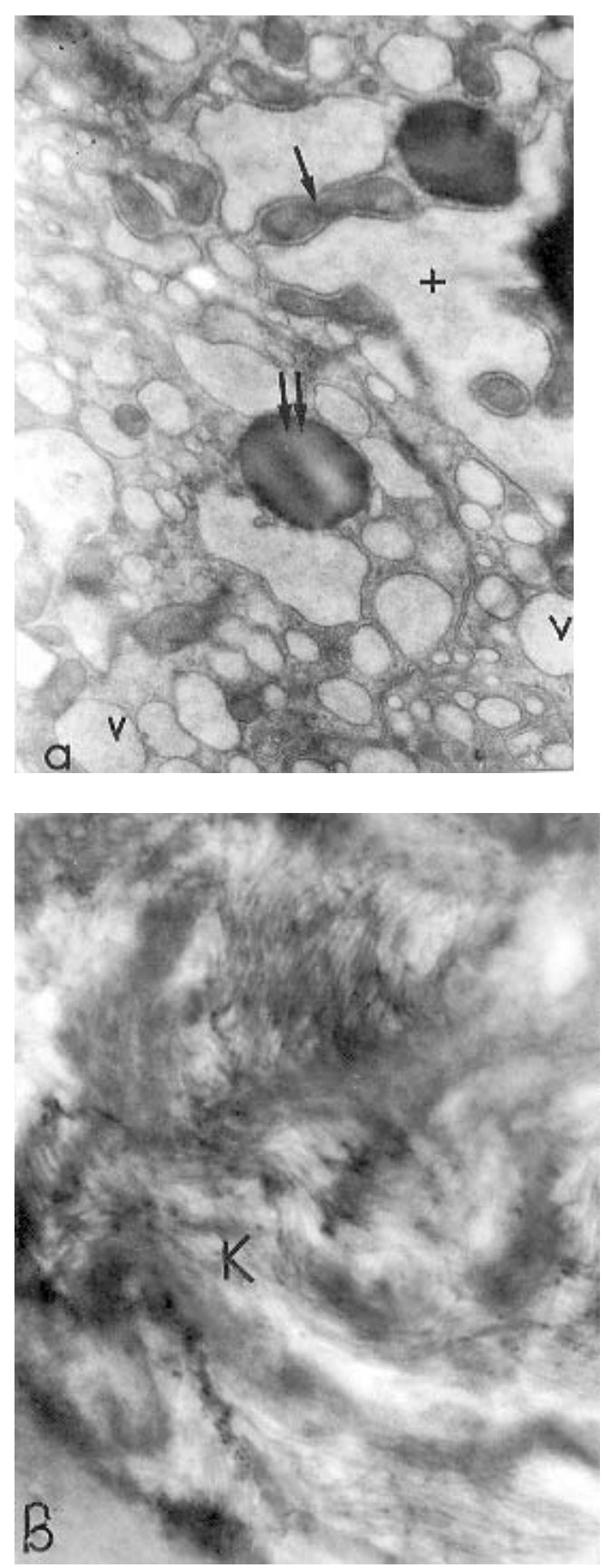

Figure 1. Group 2: a). Intracellular oedema $(+)$ in the cytoplasm of alveolocyte, $(V)$ vacuolization of endoplasmic reticulum, homogenization of mytochondria $(\downarrow)$ were seen (x 25000).

$(\downarrow \downarrow)$ Lipids

b) Increased collogen fibrilles (K) in interseptal zone (x 15000). 

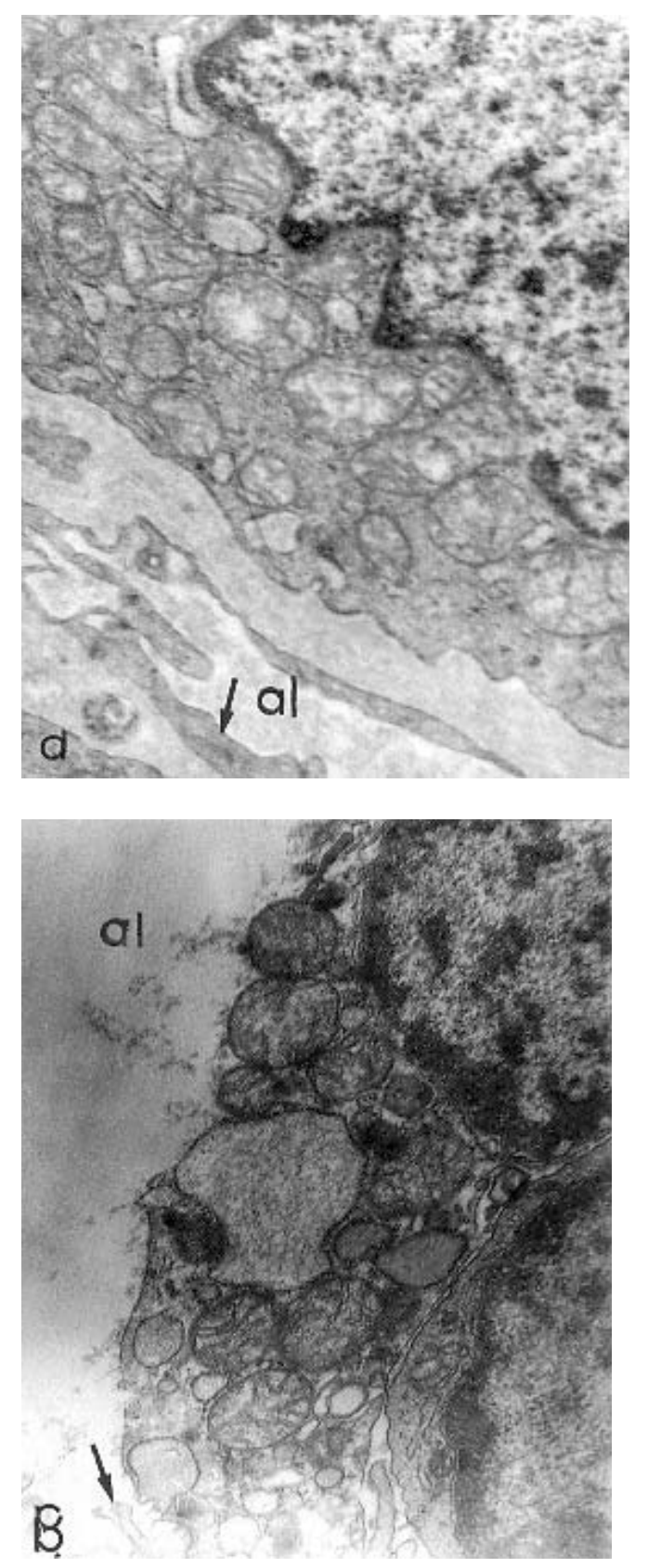

Figure 2. Group 1: a) Major processus of epithelial cells $(\downarrow)$ are intact and cytoplasmic organels of alveolocyte are saved (x 20000).

(al) Alveolar lumen

b) Cytoplasmic organels of alveolocyte are normal. Alveolocyte microvillus are intact.

(al) Alveolar lumen 